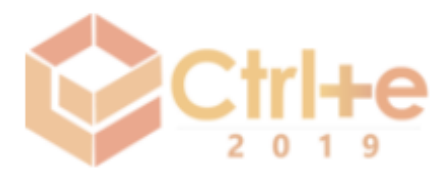

IV Congresso sobre Tecnologias na Educação (Ctrl+E 2019)

Recife, Pernambuco - Brasil

28 a 30 de agosto de 2019

\title{
Pensamento Computacional e Gênero: Avaliando Competências em Séries do Ensino Fundamental II
}

\author{
Silvana da Silva Serafim Luiz ${ }^{1}$, Vanessa Farias de Dantas² \\ ${ }^{1}$ Centro de Ciências Aplicadas e Educação - Universidade Federal da Paraíba (UFPB)

$$
\begin{gathered}
\text { 58297-000 - Rio Tinto - PB - Brasil } \\
\text { silvana.silva@dce. ufpb.br, vanessa@dce. ufpb.br }
\end{gathered}
$$

\begin{abstract}
Computational thinking is a way of thinking about problem solving so that the expression of that solution is understood by a human or machine. This paper proposes an evaluation of the pillars of Computational Thinking in the early grades of Elementary School II making comparisons and observations according to grades and genres. Given the data and analysis performed it could be concluded that there are no significant differences in skills between the grades and genders of the participating students, but the result was not conclusive due to the size of the sample and the need to cross other data that come to influence the results.
\end{abstract}

Resumo. O pensamento Computacional é uma maneira de pensar em soluções de problemas de modo que a expressão dessa solução seja entendida por um humano ou máquina. Este artigo propõe uma avaliação dos pilares do Pensamento Computacional nas séries iniciais do Ensino Fundamental II fazendo comparações e observações de acordo com séries e gêneros. Diante dos dados e análises realizadas poderia se chegar à conclusão que, não existem diferenças significativas nas habilidades entre as séries e gêneros dos alunos participantes, porém o resultado não foi conclusivo devido à o tamanho da amostra e a necessidade do cruzamento de outros dados que venham a influenciar os resultados.

\section{Introdução}

Com o rápido crescimento computacional e tecnológico ocorrido no mundo moderno, surge a necessidade de ensinar, desde a educação básica, conceitos fundamentais da Ciência da Computação como forma de melhorar o aprendizado escolar dos indivíduos e possibilitar o uso mais eficaz dessas tecnologias em benefício da sociedade, e ainda desenvolver a capacidade de resolver problemas pelos estudantes, além de apoiar e relacionar-se com outras ciências (França, 2015).

Para Brackmann (2017), o Pensamento Computacional é uma abordagem de ensino que usa diversas técnicas oriundas da Ciência da Computação e vem gerando um novo foco educacional no quesito inovação nas escolas mundiais como um conjunto de competências de solução de problemas que devem ser compreendidas por uma nova geração de estudantes em conjunto com as novas competências do século XXI, sendo uma habilidade básica, assim como ler e escrever.

Atividades que desenvolvem o Pensamento Computacional vêm proporcionando a estudantes a capacidade de adquirir habilidades analíticas, despertando também o 
interesse pela área de Computação. Esse ganho de profissionais vem sendo bastante vantajoso para as indústrias de tecnologia, porém ainda é notória a reduzida presença feminina, que pode estar ligada a estereótipos pré-definidos pela sociedade. Um deles seria a crença de que meninas teriam menos habilidade para as Ciências Exatas do que os meninos.

Silva (2017) relata que essa disparidade de gênero é evidente em cursos técnicos e de graduação na área da Computação e tecnologia em geral, e gera reflexos no mundo do trabalho, sobretudo no número de profissionais formados na área. Neste sentido, é preciso elaborar ações que busquem incentivar a figura feminina a exercer funções da área de Exatas, sendo possível formar progressivamente mais profissionais na área, posto que a Ciência da Computação, enquanto mercado em expansão, se destaca como um dos atuais pilares econômicos da sociedade, exigindo uma gama cada vez maior de profissionais (Silva apud Ashcraft, 2012).

Brackmann (2017, apud National Research Council 2011, p. 5) destaca um outro desafio como sendo a falta de metodologia adequada para avaliação do Pensamento Computacional em escolas primárias. Relata ainda que, até o momento, são escassos os trabalhos e propostas neste domínio da avaliação das aprendizagens no quadro do Pensamento Computacional. Dentre os citados em seu trabalho, destaca a metodologia proposta por Román-Gonzáles, em que seu teste de Pensamento Computacional passou por um rigoroso processo de validação e que culminou em uma tese de doutorado (Román-González, 2016).

Por se tratar de um teste validado, este foi o escolhido para a presente pesquisa, buscando assim obter resultados mais consistentes que possam ser comparados com outros trabalhos. Os aspectos principais deste trabalho são "avaliação de pensamento computacional" e "gênero", definidos como tópicos relevantes, atuais e importantes para a educação em Computação.

O trabalho está estruturado da seguinte maneira: a seção 2 trata sobre como vem sendo avaliado o Pensamento Computacional. Na seção 3, é discutida a participação feminina na Computação, seja no mercado de trabalho ou nas escolas. A seção 4 apresenta a metodologia utilizada na pesquisa, e a seção 5 detalha a aplicação dos testes. Na seção 6 são analisados os resultados obtidos, e na seção 7 são discutidas as conclusões e possíveis trabalhos futuros.

\section{Avaliação do Pensamento Computacional}

Araújo (2016) traz a avaliação como fator crucial quando se propõem práticas pedagógicas, sendo necessária para levantar dados mensuráveis capazes de verificar se uma prática pedagógica é mais eficiente que outra para estimular certa habilidade em um grupo de alunos. Destaca ainda que, se forem utilizados instrumentos inadequados ou de baixa qualidade para avaliar os alunos, corre-se o risco de não saber de fato qual a influência que a atividade provocou.

A respeito da Avaliação do Pensamento Computacional, encontram-se na literatura relatos que dizem que é um ponto bastante discutido, porém sem consenso acadêmico, citando-se a necessidade de uma devida avaliação e definição de atributos que permitam aos professores avaliar o que os estudantes aprenderam, contribuindo assim para um caminho de sucesso do Pensamento Computacional no currículo escolar. Relacionando-se o que já existe de avaliação, foram encontradas pesquisas que utilizam uma linguagem de programação (e.g. Python) e programação visual (e.g. Scratch), sem 
ênfase na Programação Desplugada (Brackmann, 2017 apud Boucinha, 2017; Grover, 2013).

Para a avaliação do Pensamento Computacional, França (2013) em seu projeto, que se tratava de uma oficina de Scratch, avalia os principais artefatos desenvolvidos, analisando a coleção de trabalhos construídos ao longo do tempo, levando em consideração a natureza evolutiva, e o desenvolvimento de um portfólio dos pares de aprendizes, em vez de, por exemplo, analisar um único projeto desenvolvido ao final do curso e a correta utilização de conceitos computacionais na sua implementação.

Brackmann (2017) traz em seu trabalho um instrumento avaliativo denominado Teste do Pensamento Computacional desenvolvido pelo pesquisador espanhol Román González e traduzido para o Português (Brasil). É composto por 28 questões que tentam identificar competências de formação e solução de problemas, baseando-se nos conceitos fundamentais da Computação, além de utilizar sintaxes lógicas usadas nas linguagens de programação, e inclui conceitos dos quatro pilares do Pensamento Computacional: Abstração, Decomposição, Reconhecimento de Padrões e Algoritmos. As questões contidas nos testes são do tipo múltipla escolha, sendo quatro alternativas a serem consideradas com apenas uma correta.

\section{Participação feminina na Computação}

Segundo dados do último Censo do Instituto Brasileiro de Geografia e Estatísticas (IBGE), cerca de $78 \%$ dos ingressantes nos cursos de Computação são estudantes do sexo masculino e apenas $22 \%$ são do sexo feminino (Silva, 2015). E ainda, segundo dados da PNAD divulgados em 2016, a maioria das mulheres que ingressam no ensino superior em áreas tecnológicas, abandonam o curso no primeiro ano. Em relação aos ingressantes em cursos de Computação, o percentual fica em torno de $10 \%$ a $12 \%$ em universidades como Unicamp, UFRJ e UFMG (Brackmann, 2017). Nota-se, a partir destes dados, que mesmo as mulheres tendo conquistado um espaço mais uniforme em meio à sociedade atual, a desigualdade de gênero é ainda muito presente nesta área.

Em uma pesquisa que buscou identificar as dificuldade de ingresso e permanência do público feminino no curso de Engenharia e Ciências da Computação no estado da Bahia, chamam atenção alguns resultados: enquanto $32 \%$ dos alunos já tiveram algum contato com a programação, apenas $17 \%$ das alunas declararam ter experiência anterior; a aprovação na disciplina de Introdução à Programação é maior para os alunos (66\%) do que para as alunas (56\%); e $61 \%$ das alunas declararam ter inibição para questionar em aula, contra apenas $29 \%$ dos alunos (Sales, 2014).

Um outro aspecto levado em consideração em várias pesquisas relacionadas à participação feminina na área de Exatas é o estereótipo que se cria de que Matemática é coisa de menino. Silva (2008) destaca que a Ciência e a Matemática são apresentadas como atividades predominantemente masculinas, criando entre os profissionais da educação estereótipos sobre a masculinidade e a feminilidade, gerando expectativas em relação ao desempenho escolar masculino e feminino, respectivamente.

Esta situação tornou-se preocupante para muitos pesquisadores, principalmente porque hoje se fala muito em desigualdade social que esteja ligada a raça, sexualidade, gênero, e um dos principais objetivos destes pesquisadores é tornar a sociedade mais inclusiva e uniforme de maneira que venha beneficiar a todos de modo igualitário, dando os mesmos salários e oportunidades em cargos de liderança, ajudando também o mercado tecnológico a criar produtos mais diversificados. 


\section{Metodologia}

Entende-se que este trabalho se trata de um estudo quantitativo baseado em análises descritivas, pois para interpretação dos dados coletados utilizou-se estatística descritiva como médias e somatórios, fazendo-se inferência a esses números. A pesquisa teve como público-alvo alunos e alunas do Ensino Fundamental II de uma escola da cidade $\mathrm{X}$. Quanto à escolha da amostra, todos os alunos das turmas foram convidados a resolver o teste, sendo assim não houve seleção de discentes, porém nem todos participaram. Também é importante destacar que os alunos não tiveram nenhum contato anterior com atividades do Pensamento Computacional.

Para identificar trabalhos que abordassem Pensamento Computacional e gênero, foi feita uma pesquisa bibliográfica, e verificou-se que podem existir outros trabalhos, mas são desconhecidos. Os achados fazem breves destaques sobre a concepção do tema, como por exemplo Brackmann (2017) que, após tabulação e análise dos dados colhidos em sua pesquisa no Brasil e na Espanha, buscou avaliar competências do Pensamento Computacional, e constatou que, na Espanha, houve uma melhoria mais significativa no gênero masculino, ao contrário do Brasil, em que o gênero feminino revelou maior destaque com relação à melhoria de desempenho.

A pesquisa bibliográfica também ajudou a identificar o instrumento avaliativo a ser utilizado nesta pesquisa: o Teste do Pensamento Computacional proposto por Román González (2016) e traduzido para o Português (Brasil) por Brackmann (2017). Previamente descrito na seção 2 deste artigo, o teste mostrou-se adequado para a faixa etária escolhida e poderia ser aplicado sem necessidade de internet.

\section{Aplicação do Teste}

O Teste do Pensamento Computacional foi aplicado com alunos das turmas iniciais do Ensino Fundamental II, sendo $6^{\circ}$ e $7^{\circ}$ ano da Escola Estadual X, localizada em uma aldeia indígena no município $\mathrm{Y}$. Os alunos são, em sua grande maioria, filhos de agricultores, trabalhadores rurais e pescadores.

De início, o teste seria aplicado em papel, com folhas contendo as 28 questões e uma folha resposta, mas, devido a problemas de impressão e da má resolução das imagens, foi necessário usar uma estratégia diferente. Optou-se então por disponibilizar o documento do teste em formato PDF nas dez máquinas do laboratório de informática da escola, e entregar uma folha resposta a cada aluno. Devido ao número pequeno de computadores, as turmas foram divididas em grupos de dez alunos para que assim fosse possível aplicar o teste individualmente.

Cada turma levou de 45 a 50 minutos para responder o teste completo. A distribuição dos sujeitos participantes da pesquisa pode ser observada na Tabela 1.

Tabela 1: Distribuição dos participantes da pesquisa

\begin{tabular}{|c|c|c|c|c|}
\hline \multirow{2}{*}{ Ano } & \multirow{2}{*}{ Idade Média } & \multicolumn{2}{|c|}{ Sexo } & \multirow{2}{*}{ Total } \\
\cline { 3 - 5 } & & Masculino & Feminino & \\
\hline $6^{\circ}$ & 13,11 & 9 & 8 & 17 \\
\hline $7^{\circ}$ & 13,08 & 6 & 6 & 12 \\
\hline Total & & 15 & 14 & 29 \\
\hline
\end{tabular}


Após a aplicação do teste nas turmas, procurou-se analisar o resultado através da obtenção de uma média aritmética simples, levando-se em consideração as respostas que foram marcadas corretamente. Houve também uma separação desses dados por série e sexo, para que os resultados fossem analisados também individualmente, procurando assim observar diferenças significativas nesses grupos.

\section{Resultados e discussões}

Foi feita uma média aritmética simples da amostra obtida a partir do teste do Pensamento Computacional, que pode ser observada na Tabela 2, sendo a média de acertos considerando o total de questões do teste, ou seja, as 28 questões.

Tabela 2: Média aritmética simples da amostra

\begin{tabular}{|c|c|c|c|}
\hline \multirow{2}{*}{ Ano } & \multirow{2}{*}{ Média } & \multicolumn{2}{|c|}{ Média por Sexo } \\
\cline { 3 - 4 } & & Masculino & Feminino \\
\hline $6^{\circ}$ & 9,1 & 9,5 & 8,7 \\
\hline $7^{\circ}$ & 10,5 & 11,5 & 9,5 \\
\hline Total & 9,8 & 10,5 & 9,1 \\
\hline
\end{tabular}

Além disso, os resultados foram agrupados de acordo com cada turma, e nessas turmas foram observados também os dados obtidos por habilidades e entre os sexos. Após a realização dessas análises, foram criados três gráficos para cada série: um primeiro gráfico para mostrar a quantidade de respostas corretas de cada questão do teste; um segundo gráfico para evidenciar o aspecto sexo (gênero) na análise do primeiro gráfico; e um terceiro gráfico para mostrar o total de pontos obtidos agrupados por habilidades, seguindo o quadro de habilidades proposto por Brackmann (2017). Esses pontos foram calculados fazendo-se a soma do total de acertos de cada questão de acordo com a(s) habilidade(s) que a mesma avalia. Todos os gráficos e resultados são detalhados nas seções a seguir.

\subsection{Resultados do $6^{\circ}$ ano}

Nesta turma, responderam ao teste um total de 17 alunos, sendo 9 meninos e 8 meninas, como já indicado na Tabela 1. De acordo com o Gráfico 1, percebe-se que as questões que tiveram pelo menos cinco acertos foram as questões, 4, 5, 10,11, 12, 16, 18 e 20, e as que tiveram de 10 a 14 acertos, o maior número alcançado, foram as questões 1, 2, 3, $6,9,21$ e 26 . As questões 8 e 22 não tiveram nenhum acerto nesta turma. 


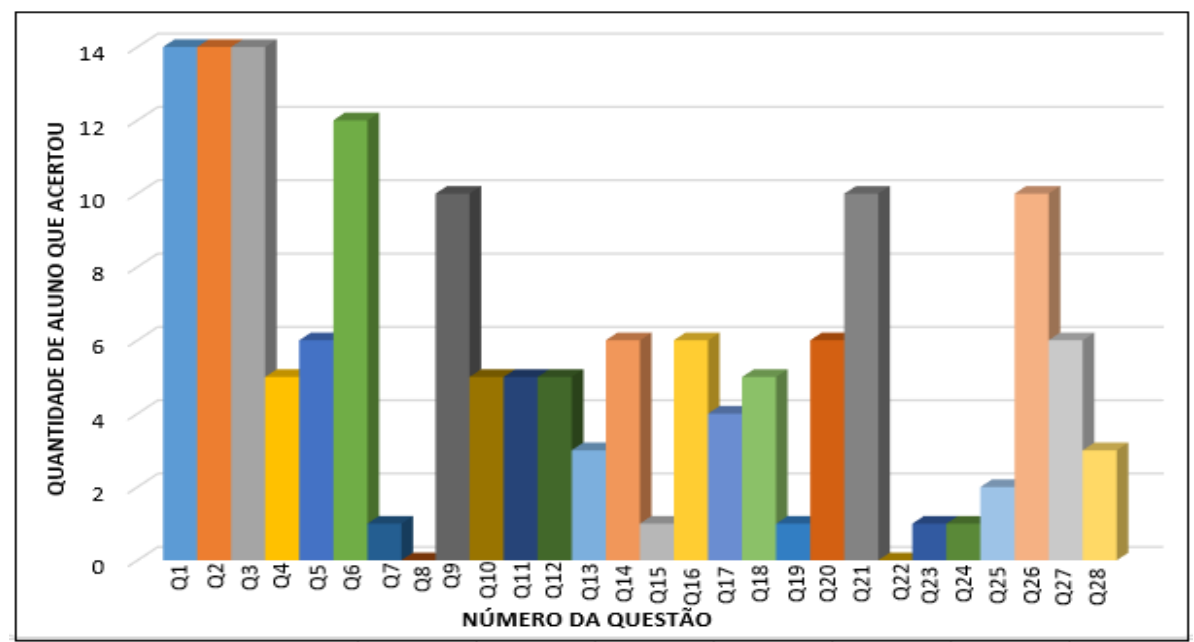

Gráfico 1: Quantidade de acertos por sexo - 6o ano

Quando se observa o Gráfico 2, é possível notar que, comparando-se os acertos entre os sexos, os meninos alcançaram um número maior, com exceção da questão 26. Quando se observa as médias aritméticas simples já apresentadas na Tabela 2, também é possível notar uma pequena diferença favorável aos meninos.

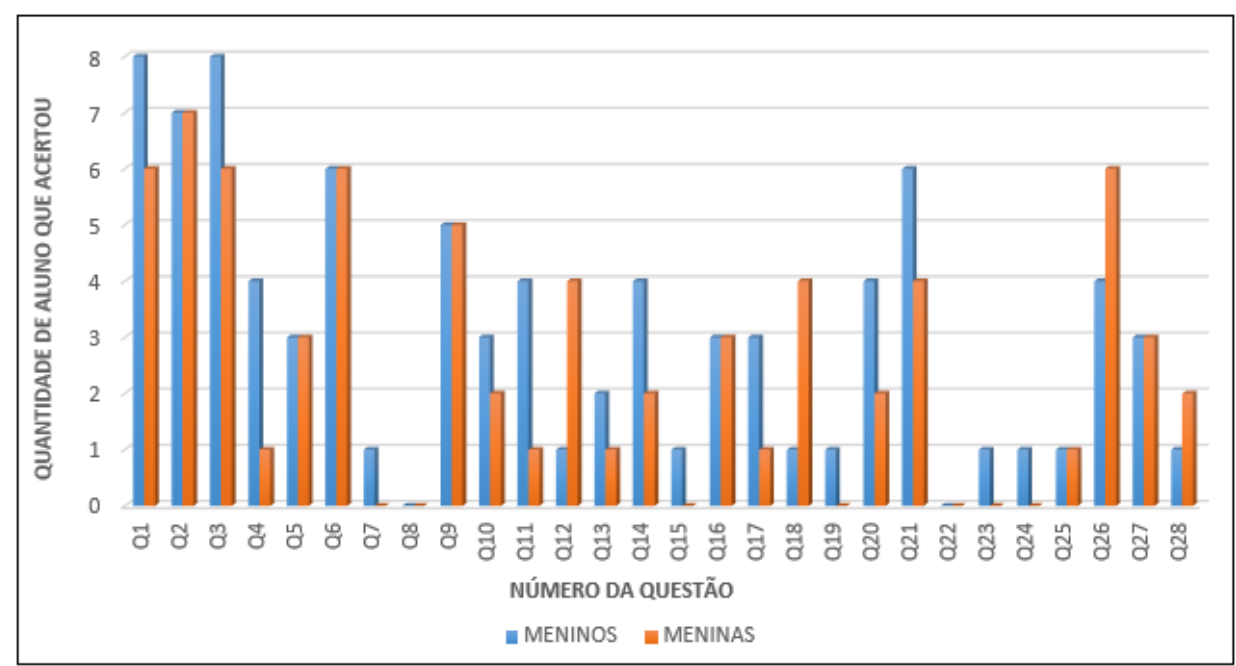

Gráfico 2: Quantidade de acertos por questões - 60 ano

\subsection{Resultados do $7^{\circ}$ ano}

Participaram do teste um total de 12 alunos, sendo 6 meninos e 6 meninas. No quadro geral de notas do teste do Pensamento Computacional, a média geral foi 10,5. Os meninos obtiveram uma média de 11,5 e as meninas de 9,5 , o que dá um total de dois pontos de diferença, um número que chamou a atenção devido à quantidade de amostras serem iguais.

No Gráfico 3, pode-se observar que o maior número de acertos foi de 12 questões, e as questões 8 e 22 ninguém conseguiu acertar. 


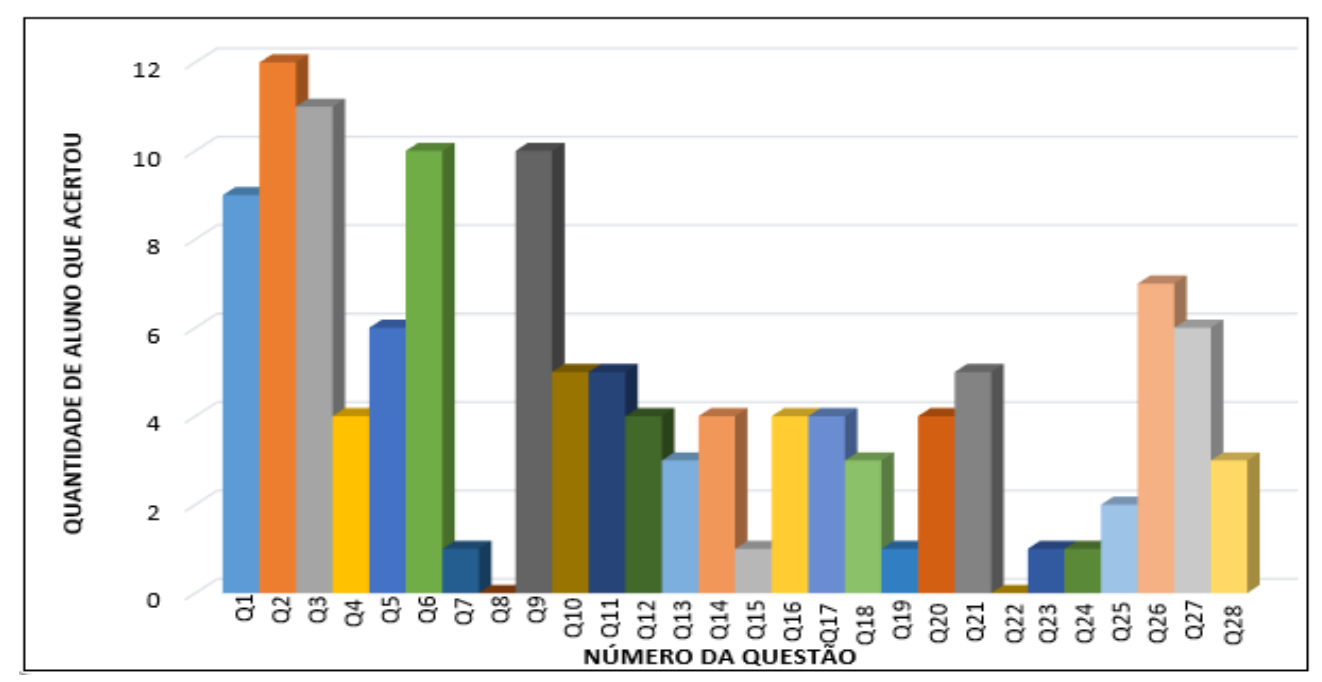

Gráfico 3: Quantidade de acertos por questões $-7^{\circ}$ ano

No Gráfico 4, é possível fazer comparações dos acertos de cada questão entre os sexos. Nesta turma, observa-se que as meninas conseguiram um maior número de acertos em relação aos meninos nas questões $6,12,18,26$ e 28, mas também houve questões em que não conseguiram nenhum acerto, como em 7, 19, 23 e 24. Assim como ocorreu com a turma de $6^{\circ}$ ano, não houve acertos para as questões 8 e 22.

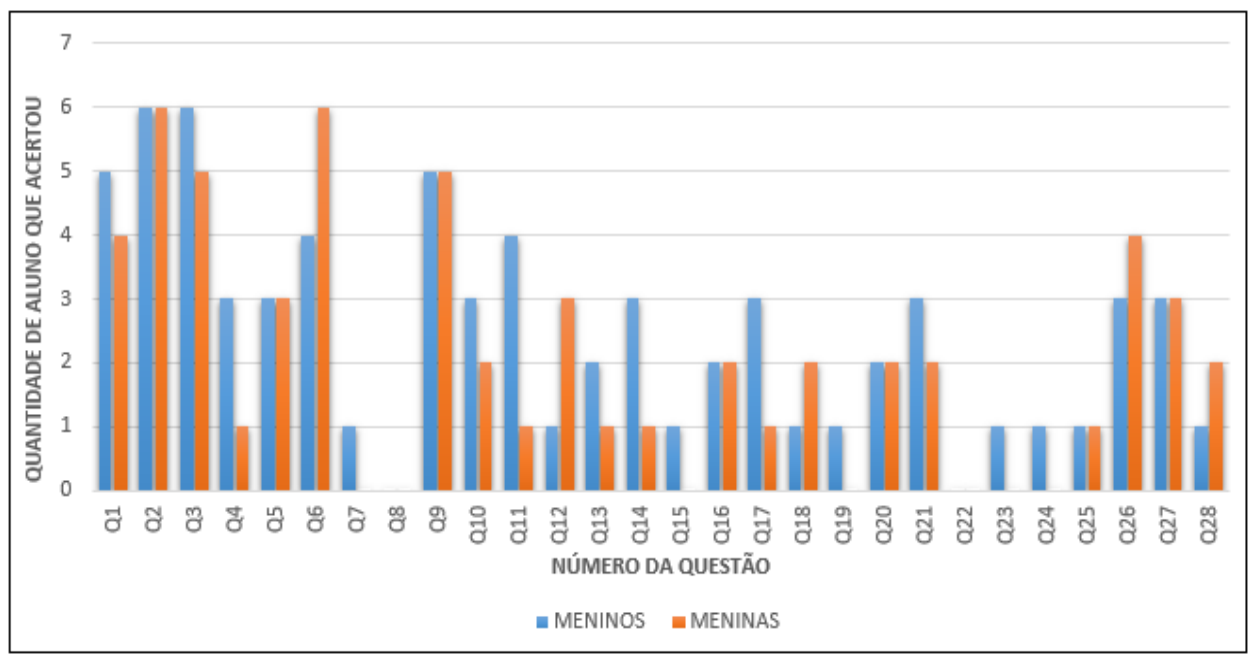

Gráfico 4: Quantidade de acertos por sexo - 7º ano

\section{Conclusão e Trabalhos Futuros}

O Pensamento Computacional vem se consolidando como um importante diferencial para aqueles que desejam se destacar no mercado de trabalho, e também como um importante conteúdo a ser explorado nas escolas em geral desde as séries iniciais. Porém, ainda não há uma quantidade razoável de estudos que se preocupem em medir o Pensamento Computacional no Ensino Fundamental. Especialmente, não há conhecimento sobre trabalhos considerando aspectos específicos como gênero nessas medições, para identificar se algumas das crenças comumente propagadas culturalmente, como a de que as meninas seriam menos aptas às carreiras das áreas de Ciências Exatas que os meninos, realmente têm algum fundamento estatístico.

Dessa forma, o presente trabalho procurou avaliar os quatro pilares do Pensamento Computacional, sendo eles, Abstração, Decomposição, Reconhecimento de 
Padrões e Algoritmo, dos estudantes participantes, verificando e comparando os resultados obtidos entre séries e entre gêneros. A execução da pesquisa também possibilitou aos envolvidos o contato com uma nova maneira de pensar e observar para responder a um teste, e o entusiasmo e a curiosidade dos mesmos ao responder as questões foi notável.

Quanto aos resultados obtidos, é possível notar que na turma do $6^{\circ}$ ano, os meninos, no geral, conseguiram acertar um maior número de questões. Já na turma do $7^{\circ}$ ano, ambos os sexos acertaram a mesma quantidade de itens, o que sugere uma equivalência de competências. Porém, devido à amostra ser muito pequena, os resultados ainda não podem ser considerados do ponto de vista da relevância estatística, e estudos mais amplos e aprofundados são necessários para que se possa afirmar se esse padrão se repete.

Também é possível notar que não houve uma evolução das habilidades nos anos letivos participantes da amostra, sendo necessário um estudo mais aprofundado para identificar as razões pelas quais discentes de $7^{\circ}$ ano chegam a ter desempenhos inferiores aos de $6^{\circ}$ ano. No geral, o número de questões corretas respondidas no teste foi entre 4 e 14, em um total de 28 questões, com uma média total de 9,8. As questões mais acertadas foram as mais simples do teste, e também as questões mais próximas do exemplo I do teste. Algumas até trabalhavam laços de repetição, mas questões envolvendo laços de repetição aninhados foram as menos acertadas.

Como trabalho futuro, planeja-se analisar uma quantidade maior de alunos em relação à amostra atual como também se viu a necessidade de cruzar mais dados sobre a amostra, como por exemplo, outras características, além do gênero, que podem influenciar no desempenho dos alunos, como habilidade com Matemática. Diante dos fatos levantados, também seria necessário fazer um trabalho que buscasse estimular as habilidades dos alunos, com aulas de Pensamento Computacional, buscando assim contribuir para a melhoria do processo de ensino aprendizagem nas escolas, e para mais evidências de que o PC é uma abordagem de ensino eficiente no ambiente escolar, buscando sempre desenvolver as habilidades necessárias para a sociedade.

\section{Referências}

BRACKMANN, C. P. Desenvolvimento do Pensamento Computacional através de atividades desplugadas na educação básica. Programa de Pós-Graduação em Informática na Educação (PPGIE). UFRGS, 2017.

FRANÇA, R. S.; TESDECO, P. C. A. Desafios e oportunidades ao ensino do pensamento computacional na educação básica no Brasil. Anais dos Workshops do IV Congresso Brasileiro de Informática na Educação (CBIE 2015).

SAlES, A.; CALADO, B.; SIlVA, D. R. D.; MATTOS G. O.; MOREIRA, J. A. dificuldades para o ingresso e permanência na ciência e engenharia da computação: um olhar feminino. XXXIV Congresso da sociedade brasileira de computação CBIE 2014.

SBC - Sociedade Brasileira de Computação. Trabalho sobre Pensamento Computacional é destaque na Globo. 2018. Disponível em: $<$ http://www.sbc.org.br/noticias/10-slideshow-noticias/2071-trabalho-sobrepensamento-computacional-e-destaque-na-globo $>$ Acesso em: agosto de 2018.

SCHOEFFEL, P.; MOSER, Paolo; VARELA, G. M.; DURIGON, L. R.; ALBUQUERQUE, G. C.; NIQUELATI, S. Uma Experiência no Ensino de 
Pensamento Computacional e Fomento à Participação na Olimpíada Brasileira de Informática com Alunos do Ensino Fundamental. IV Congresso Brasileiro de Informática na Educação (CBIE 2015).

SILVA, A. P. S.; FRANCO, J. S. S.; JUNIOR, J. C. L. Desenvolvimento do Pensamento Computacional e discussões sobre representação feminina na Computação: um estudo de caso. VI Congresso Brasileiro de Informática na Educação (CBIE 2015).

SILVA, C. P. Silvério. Diferenças de desempenho em matemática: Um olhar a partir da perspectiva de gênero. $2^{\circ}$ SIPEMAT-Simpósio Internacional de Pesquisa em Educação Matemática (2008).

SILVA, V.; SOUZA, A.; MORAIS, D. Pensamento Computacional: Um relato de práticas pedagógicas para o ensino de Computação em escolas públicas. Revista Tecnologias na Educação. Ano 8. Número/Vol.16. Edição Temática. Congresso Regional sobre Tecnologias na Educação (Ctrl+E 2016). Disponível em: $<$ tecnologiasnaeducacao.pro.br $>$ Acesso em 23 de agosto de 2018. 